\title{
A PEDAGOGIA HISTÓRICO-CRÍTICA E A LUTA PELA FORMAÇÃO HUMANA PLENA DE CONTEÚDOS: O CASO DA CULTURA CORPORAL NA EDUCAÇÃO ESCOLAR DO MST
}

\author{
Isis Conrado Haun ${ }^{1}$ \\ Katiusca Lima Cunha ${ }^{2}$ \\ Tiago Nicola Lavoura ${ }^{3}$
}

\section{RESUMO}

O presente artigo investigou os fundamentos pedagógicos do trabalho educativo escolar do Movimento dos Trabalhadores Rurais Sem Terra e sua relação com o ensino da cultura corporal. A pesquisa é de caráter bibliográfico e documental, complementada por uma etapa de pesquisa exploratória no Assentamento Terra Vista do MST, no município de Arataca - BA. Os dados da pesquisa apontam a pedagogia dos projetos fundamentando o trabalho educativo do MST, evidenciando-se fragilidades para o processo de formação e emancipação humana respaldados pelas bandeiras de luta do movimento. Defendemos a pedagogia histórico-crítica enquanto teoria pedagógica balizadora do trabalho educativo do MST, visto sua tese de que o processo educativo escolar é um processo criador de carecimentos superiores, voltado para a formação humana dos indivíduos não fundamentada na satisfação das necessidades já dadas pela vida cotidiana, mas sim pelo contato com conteúdos socialmente produzidos e integrantes da esfera da vida nãocotidiana.

Palavras-chaves: Pedagogia histórico-crítica; Educação do campo; Cultura corporal.

\section{THE HISTORICAL-CRITICAL PEDAGOGY AND THE STRUGGLE FOR HUMAN FULL EDUCATION CONTENT: THE CASE CORPORAL CULTURE OF SCHOOL EDUCATION MST}

\begin{abstract}
This paper investigates the pedagogical foundations of the educational school of the Movement of Landless Rural Workers and its relation to the teaching of corporal culture. The research is bibliographical and documentary, complemented by a stage of exploratory research in Terra Vista MST settlement in the municipality of Arataca - BA. The research data indicate pedagogy projects basing the educational work of the MST, demonstrating weaknesses in the process training and human emancipation backed by political demands of the movement. Defends the historical-critical pedagogy as a pedagogical theory Buoy educational work of the MST, as his thesis that the process of school education is a process of creating greater privations, facing the human individuals not based on satisfying the needs already given for everyday life, but by contact with socially produced content and members from the sphere of non-life everyday.
\end{abstract}

Keywords: Historical-critical pedagogy. Education Field. Corporal culture. 


\section{INTRODUÇÃO}

Esta pesquisa possui como objeto os fundamentos da cultura corporal na educação escolar do MST, tendo como objetivo apreender os fundamentos pedagógicos do trabalho educativo escolar do Movimento dos Trabalhadores Rurais Sem Terra e sua relação com o ensino da cultura corporal ${ }^{4}$.

Desta forma, pretendeu-se investigar as bases teóricas do trabalho pedagógico no ensino da cultura corporal na educação escolar do MST as quais contribuam para o processo de formação dos indivíduos e para a luta mais geral da emancipação humana.

Partimos da defesa da tese de que a educação do MST deve estar atrelada ao acesso ao conhecimento científico, artístico e filosófico e, ainda, que corresponda ao papel de mediação no seio da prática social global (SAVIANI, 2008), ou seja, uma educação a qual possibilite uma formação humana consciente e, ao mesmo tempo, geradora de carecimentos (DUARTE, 1993), levando os indivíduos à busca de uma prática social a qual permita o gozo de uma atividade livre, universal e criativa, bem como o usufruto da arte, da literatura, da música, do jogo e do esporte, da dança, da ginástica, enfim, de tudo aquilo que chamamos de cultura, mesmo que ainda na complexa e contraditória totalidade das relações sociais do modo de produção capitalista.

A defesa da escola e de sua função de mediação no seio da prática social global corresponde à necessidade de se pensar o trabalho educativo e seus fundamentos enquanto mediação na e da vida social dos indivíduos os quais vivem no campo e, em especial, nas áreas de reforma agrária. Desta feita, entendemos como fundamental realizar a defesa do papel da educação escolar de socialização do saber sistematizado na sua forma mais elaborada (OLIVEIRA; DUARTE, 1990; SAVIANI, 2008), a defesa da mediação da escola e do trabalho escolar na apropriação dos conhecimentos os quais possibilitem aos indivíduos o acesso ao conjunto de objetivações historicamente produzidas pela humanidade.

Isto porque o acesso ao patrimônio imaterial já construído historicamente e acumulado socialmente pela humanidade é fundamental para o processo de formação humana de cada indivíduo singular. Neste sentido, os indivíduos - notadamente os trabalhadores do campo e os integrantes do MST - devem lutar por condições de usufruto deste conjunto de atividades as quais são produções da humanidade, incluídos os conteúdos da cultura corporal os quais se materializam nas diferentes formas de jogos, de esporte, de lutas, de ginástica, de dança, de formas de exercitar e conhecer o corpo, enfim, diferentes formas de objetivação da corporalidade determinadas em última instância pela necessidade de existência dos homens.

A partir dos pressupostos teórico-metodológicos do materialismo históricodialético, a pesquisa se caracterizou enquanto pesquisa bibliográfica e documental, complementada por uma etapa de pesquisa exploratória partindo de entrevistas estruturadas (GIL, 1999).

A análise documental considerou o conjunto de referências, direcionamentos e orientações os quais demarcam os Projetos Políticos Pedagógicos do setor educacional do MST em uma área de reforma agrária localizada no município de Arataca, região sul da Bahia. A análise de conteúdo (RICHARDSON, 1999) realizada no Programa de Ensino do componente curricular Educação Física do Centro Estadual de Educação Profissional do Campo Milton Santos (CEEP), bem como, na transcrição das entrevistas estruturadas realizadas com a única professora de Educação Física desta escola permitiram expor dados 
empíricos sobre a apropriação da cultura corporal e suas possibilidades formativas, na perspectiva da emancipação humana e superação da sociedade de classes.

O trabalho atendeu as recomendações da Resolução $n^{\circ}$ 196/96 do Conselho Nacional de Saúde para estudos com seres humanos. Houve a assinatura do Termo de Consentimento Livre e Esclarecido, sendo o estudo aprovado pelo Comitê de Ética em Pesquisa da Universidade Estadual de Santa Cruz e registrado na forma de parecer consubstanciado de $\mathrm{n}^{\circ} 625$ em 23 de fevereiro de 2011.

\section{O MST, A LUTA PELA TERRA E PELA EDUCAÇÃO}

Conforme Araújo (2007), as lutas pela posse da terra e movimento de resistência contra a exploração dos trabalhadores tiveram início com a invasão do território indígena, perpassou pelo movimento de luta contra o cativeiro e a exploração dos escravos e, posteriormente, alcançou os imigrantes que lutaram para sobreviver em terras brasileiras.

O MST surgiu quando centenas de trabalhadores rurais expulsos por um projeto autoritário para o campo brasileiro - capitaneado pela ditadura militar que então cerceava direitos e liberdades de toda a sociedade - decidiram fundar um movimento social camponês, autônomo, que lutasse pela terra, pela reforma agrária e pelas transformações sociais necessárias para o nosso país (MST, 2009).

Oficialmente fundado em Cascavel, no estado do Paraná, no I Encontro Nacional em 1984, o MST se transformou em um marco na nova forma de luta pela terra no Brasil, consolidando ao longo dos anos um movimento com um projeto histórico social claro e definido que tem como objetivos: lutar pela terra e pela reforma agrária, lutar pela superação da sociedade de classes e pelo modo do capital organizar a vida (ARAÚJO, 2007).

Nos últimos anos, para além da luta pela terra, a luta pela educação do campo vem conquistando espaço nos debates e nas políticas educacionais no Brasil. Com efeito, a educação do campo não emerge no vazio e nem é iniciativa das políticas públicas, mas sim fruto de um movimento social, da mobilização dos trabalhadores do campo, da luta social. Advém da organização coletiva dos trabalhadores diante do desemprego, da precarização do trabalho e da ausência de condições materiais de sobrevivência para todos.

Como se sabe, a educação do campo vem sendo reivindicada por um amplo movimento nacional desencadeado para a construção das escolas do campo, vinculadas ao processo de construção de um projeto popular para o Brasil, incluindo um novo projeto de desenvolvimento para o campo.

O MST é reconhecidamente o principal movimento de luta social o qual buscou, desde o início de sua organização, articular a luta pela terra com a luta por uma educação comprometida com a transformação social. Desde o início do Movimento, com suas primeiras ocupações, tinha-se a preocupação do que fazer com as crianças acampadas, bem como de que forma possibilitar a elas o direito constitucional à escolarização.

A análise dos fundamentos teóricos da educação do MST se revela desafiadora. Autores como Araújo (2007), Caldart (2004), D’Agostini (2009), Dalmagro (2011) e Teixeira (2009) vêm se dispondo a contribuir com o debate atual acerca da educação escolar do MST e, notadamente, constatam a presença de elementos contraditórios neste âmbito.

Escapa-nos aqui a possibilidade de debate acerca dos fundamentos teóricos pedagógicos mais gerais os quais pautam a educação do MST como um todo. Em virtude do espaço delimitado para a construção deste artigo, tal qual seu objeto de pesquisa, não 
nos é possível desenvolver uma análise séria e comprometida explicitando as bases definidoras da educação do Movimento.

Não obstante, cabe salientar que muitas das aproximações e filiações da educação do MST com determinadas teorias pedagógicas e concepções de práticas educativas - com efeito, reconhecidamente a educação do MST se pauta na pedagogia da educação popular (Paulo Freire é sua maior expressão), na pedagogia da prática (preconizada por Miguel Arroyo e Maurício Tragtemberg), na pedagogia socialista (formulada por pedagogos na época da experiência revolucionária russa, tais como Pistrak, Krupskaya e Makarenko) e na pedagogia do movimento (a principal influência é Roseli Caldart) - acabam por fazê-lo considerar a educação escolar como conteudista, tradicionalista, cognitivista e livresca, aproximando a concepção e a prática educativa do Movimento ao ideário escolanovista porém, com certo caráter popular - o qual se destacou em nosso país no século passado.

O MST não tem dúvidas ao afirmar que aquilo que diferencia sua proposta educacional, sobretudo seu currículo escolar, das escolas e dos currículos tradicionais se expressa em duas diferenças importantes: o centro do processo de aprendizagem e ensino é retirado da sala de aula, pois, se aprende e se ensina a partir da prática e; retira-se o foco dos conteúdos escolares, passando os mesmos a serem escolhidos em função das necessidades que a prática vai criando (MST, 2005).

Ao buscar responder o questionamento sobre o que estudar nas escolas, imediatamente o MST afirma que é a realidade do Movimento a qual precisa ser estudada, conhecida e, sobretudo, transformada. Assim, privilegia-se o estudo dos temas geradores os quais advém de questões ou problemas da própria realidade, em detrimento de uma lista de conteúdos prontos e acabados abstratamente selecionados. Conforme se pode notar, "Esta é a diferença básica entre partir de temas e partir de conteúdos. Partindo de conteúdos nem sempre conseguimos levar a criança a compreender a realidade. Partindo dos temas a criança está estudando a realidade diretamente" (MST, 2005, p. 55).

Para o MST, uma educação a qual parta das experiências próximas e vivas das crianças possibilitará muito mais condições para que coloque o Movimento em condições de enfrentar os seus problemas e desafios do dia-a-dia:

De qualquer modo, o que precisa ficar claro é que quanto mais experiências práticas a criança tiver, mais sólida e significativa será sua aprendizagem e mais crítica ela se torna. Uma criança que só aprende (ou decora) informações de livros, ou o que ouve da professora, não tem condições de por em dúvida, confrontar ou criticar o que recebe; acaba submissa e obediente ao saber que lhe dizem ser verdadeiro (Ibidem, p. $60)$.

Constata-se que a caminhada para a constituição de uma escola diferenciada do MST se dá concomitantemente com determinada crítica à escola tradicional, uma bandeira típica do movimento de educação popular. A educação conscientizadora das massas, a valorização da cultura do povo e a alfabetização partindo da sua realidade, a necessidade de aproximar a intelectualidade da população - a ponto daquele aprender com o povo teve sua expressão mais acaba dada pela concepção educativa de Paulo Freire.

Saviani (2009a) assim afirma a importância deste educador em nosso país, sobretudo quando ele se lança a enfrentar os problemas de seu tempo: 
Parte-se da crítica à pedagogia tradicional (pedagogia bancária) caracterizada pela passividade, transmissão de conteúdos, memorização, verbalismo etc. e advoga-se uma pedagogia ativa, centrada na iniciativa dos alunos, no diálogo (relação dialógica), na troca de conhecimentos. A diferença, entretanto, em relação à Escola Nova propriamente dita, consiste no fato de que Paulo Freire se empenhou em colocar essa concepção pedagógica a serviço dos interesses populares. Seu alvo inicial foi, com efeito, os adultos analfabetos (p. 61).

Em seu livro História das Ideias Pedagógicas no Brasil, Saviani (2011) considera tanto a pedagogia da educação popular quanto à pedagogia da prática como ideias pedagógicas contra-hegemônicas do pensamento pedagógico nacional. Não obstante, reconhece que ambas estão centradas no saber do povo e na autonomia de suas organizações. Com tendência costumam reportar a prática educativa libertadora à margem da estrutura escolar, ao passo que, quando se reportam às escolas propriamente ditas, buscam "[...] transformá-las em espaço de expressão das ideias populares e de exercício da autonomia popular" (p. 415).

Isto claramente se evidencia na proposta educacional do MST, quando se afirma inúmeras vezes que educação é mais do que escola e que o Movimento sempre está em busca de uma formação humana mais ampliada.

Para os proponentes da pedagogia da prática, por exemplo, "Os movimentos sociais têm seu modo de conhecer a realidade [...]" sendo que "[...] o conhecimento socialmente construído é muito mais diversificado do que as áreas curriculares pensam" (ARROYO, 2003, p. 43). É por isto que "As experiências não formais de educação [...]" são "[...] mais próximas da dinâmica popular" (p. 34).

Neste sentido, as escolas do MST colocam como centro das preocupações educacionais a realidade cuja definição se aproxima ao conceito de cotidiano. Percebe-se que a educação do MST deve estar constantemente atrelada às necessidades práticas e imediatas dos acampamentos e assentamentos, o que se justifica pelos desafios imediatos do Movimento e pode ser explicado pelo contexto histórico de sua organização.

D'Agostini (2009) afirma que este entendimento da categoria realidade, presente em muitos momentos na proposta educacional do MST, acaba por ser compreendido pelo Movimento de maneira superficial e simplista, muitas das vezes tomada como cotidiano, pertencente à esfera do plano imediato e sem as mediações da análise do pensamento para que a realidade seja apreendida de maneira mais aprofundada e consciente.

Conforme Dalmagro (2011), o MST acaba por incorporar a concepção de que se deve ensinar a fazer fazendo, uma expressão a qual está ancorada na educação popular e na pedagogia da prática e que possui sua expressão maior no norte-americano J. Dewey e em sua pragmática pedagogia liberal moderna, imbuída por um menosprezo pela teoria.

$\mathrm{O}$ escolanovismo foi o carro-chefe das teorias pedagogias as quais vêm sendo denominadas de "aprender a aprender", e em determinados momentos das produções teóricas do MST, ele parece se fazer presente, na medida em que organizar o ensino para o MST não consiste em transmitir conhecimentos às crianças, "[...] mas sim em lhes dar condições para que descubram, por si mesmas, as melhores soluções" (MST, 2005, p. 8687).

Assim, pode-se apreender a secundarização da escola e do conhecimento a ser transmitido e assimilado pela educação escolar no MST. Conforme constata Santos (2012), o recuo do conhecimento científico e objetivo da realidade vem sendo uma característica 
dos movimentos de luta social nas últimas décadas. Em nome da democracia e da participação do povo, exalta-se uma perspectiva participacionista - procedendo-se conforme as impressões imediatas, os desejos, as emoções e a subjetividade - e a valorização do empirismo nas práticas educativas (SANTOS, 2012).

É o que podemos constatar também no ideário e nos fundamentos pedagógicos da pedagogia do movimento e da pedagogia da prática:

Construir o ambiente educativo de uma escola é conseguir combinar num mesmo movimento pedagógico as diversas práticas sociais que já sabemos ser educativas, exatamente porque cultivam a vida como um todo: a luta, o trabalho, a organização coletiva, o estudo, as atividades culturais, o cultivo da terra, da memória, dos afetos... [...] Trata-se de um jeito de pensar e de fazer a escola que se produz da lição de que não se pode centrar um projeto educativo em uma só pedagogia ou em um tipo de prática pedagógica apenas, por mais educativa que ela seja (CALDART, 2003, p. 74).

Para Arroyo (2003, p. 37):

Recuperar essa concepção mais alargada de educação como formação e humanização plena pode ser uma das contribuições mais relevantes da pedagogia dos movimentos para a educação formal e não-formal. Para o repensar e o agir pedagógicos. Alargar este foco supõe ver os educandos para além de sua condição de alunos, de alfabetizandos, de escolarizandos... para vê-los como sujeitos de processos sociais, culturais, educativos mais totalizantes [...].

A concepção de que a educação escolar estaria provida de todos os males e vícios da classe dominante e, mais do que isto, ser considera por si só e integralmente uma instituição burguesa responsável por inculcar conhecimentos também burgueses e valores, hábitos e comportamentos elitistas e conformadores nos parecem uma expressão acabada dos teóricos crítico-reprodutivistas da educação escolar, como já explicitara Saviani (2008, 2009a).

Reciprocamente, advogar a educação não-escolar ou não-formal enquanto um tempo e espaço desprovido das contradições e interferências da sociedade capitalista, como se fora da escola os indivíduos estivessem livres das relações sociais alienantes e alienadoras nos parece uma lógica de pensamento muito pouco dialética.

Em contraposição às ideias anteriormente colocadas, parece-nos que a pedagogia histórico-crítica pode trazer uma contribuição fundamental para a organização do trabalho educativo e a formação dos indivíduos integrantes deste movimento de luta social, visto que a mesma procura articular uma concepção dialética de história, de trabalho educativo e de formação humana.

Assim, para a pedagogia histórico-crítica - teoria pedagógica a qual emerge notadamente nos anos 80 do século passado com as contribuições de Dermeval Saviani trata-se de um equívoco secundarizar e, no limite, abrir mão da educação escolar, sobretudo quando se pensa na especificidade do trabalho educativo na escola e sua importância para o acesso ao conhecimento elaborado e sua contribuição à luta mais geral pela modificação da sociedade.

Esta teoria pedagógica não compartilha da ideia posta por alguns intelectuais da educação e por determinadas organizações sociais de que a escola não poderia contribuir 
para a luta revolucionária da classe trabalhadora, visto que ela seria uma instituição meramente reprodutora das relações sociais capitalistas. Tampouco está de acordo com aqueles que afirmam que "[...] a centralidade das atividades educativas se encontra nos saberes locais e intersubjetivos existentes num mundo diverso e complexo modulado pelas incontáveis realidades étnicas, campesinas, urbanas, cujas racionalidades e culturas são variadas" (SANTOS, 2012, p. 198).

A pedagogia histórico-crítica não nega que a produção do conhecimento é e está na prática social, tampouco não deixa de reconhecer que existem espaços formativos os quais transcendem a educação escolar, como a família, o sindicato, o partido e movimentos sociais. Porém, ela reconhece e defende a especificidade da educação escolar, a qual se diferencia dos outros espaços formativos.

Aquilo que especificamente deve ser tratado na educação escolar, por excelência, não poderá ser desenvolvido em nenhum outro espaço. E sua função de transmissão e assimilação do conhecimento sistematizado - acerca da ciência, da filosofia, da arte, da cultura corporal, dentre outros - com o intuito de fazer com que o aluno ultrapasse os níveis de conhecimento do senso comum para uma consciência filosófica (SAVIANI, 1991), ou seja, que o indivíduo transite das formas cotidianas de entendimento da realidade para as formas não-cotidianas (DUARTE, 2007) se insere na dinâmica e na luta de classes.

Entendemos que o MST deve ter acesso ao conhecimento elaborado na medida em que o mesmo se torna parte constitutiva do instrumental de luta do Movimento e da classe trabalhadora como um todo, e neste ínterim a pedagogia histórico-crítica tem algo a contribuir. Abrir mão da escola ou secundarizar sua importância não reconhecendo seu papel na formação plena dos indivíduos significa fazer "[...] coro com as propostas que visam abandonar as camadas populares a sua própria sorte em relação à formação teóricocientífica, o que repercute em maiores dificuldades para a sua organização enquanto classe para si" (SANTOS, 2012, p. 201). Nesse sentido:

[...] a pedagogia histórico-crítica tem dado sua contribuição específica considerando que, para o avanço da organização das camadas populares em direção à socialização das riquezas materiais e espirituais produzida pelo conjunto dos homens, a apropriação do conhecimento sistematizado é de extrema importância. Para isso desenvolve suas análises e proposições pedagógicas articulando o trabalho educativo aos processos de lutas sociais gerais, reconhecendo na escola o lugar por excelência da luta pela socialização do conhecimento (Ibid., p. 197).

Fica claro, portanto, que esta teoria pedagógica não compreende a educação escolar e o conhecimento sistematizado como algo nocivo às camadas populares e suas organizações, no sentido de conceber a transmissão deste conhecimento via escola uma invasão cultural e uma tentativa de dominação. Tampouco compreende que a defesa da escola e do cumprimento de sua função profícua seja uma perspectiva escolacentrista, cientificista ou um cognitivismo conteudista, conforme defende Miguel Arroyo.

Ao conceber o trabalho educativo como o ato de se produzir, de maneira direta e intencional, a humanidade em cada indivíduo singular (SAVIANI, 2008), a pedagogia histórico-crítica está se pautando na análise marxiana sobre a dialética da apropriação e objetivação do gênero humano, a qual traduz a reciprocidade entre o universal (o gênero) e o singular (o indivíduo) por intermédio da mediação particular do trabalho educativo. Neste sentido, o homem é concebido como síntese de múltiplas relações, portanto, unidade da diversidade. 
Ao defender o acesso às formas elaboradas do conhecimento, necessariamente envolvendo o distanciamento dos indivíduos do seu viver cotidiano, não se está defendendo a inculcação - via transmissão escolar - de uma cultura homogeneizada a qual não reconhece a singularidade dos indivíduos. Não se trata disso.

Trata-se de reconhecer a escola em sua função mediadora entre o conhecimento espontâneo e as formas culturais elaboradas, função esta que é uma exigência para que os indivíduos - inclusive os povos do campo - possam ir à busca de uma humanidade a qual vem sendo produzida historicamente.

Numa sociedade pautada na propriedade privada dos meios de produção e na divisão de classes antagônicas, ocorre é que suas relações alienantes e alienadoras promovem possibilidades desiguais dos indivíduos saírem em busca desta humanidade. Neste sentido, as diferenças são firmadas e ofuscadas por meio da desigualdade entre as classes. Somente em uma sociedade de iguais é que as diferenças poderão, de fato, se manifestar.

Tal feito implica, evidentemente, a superação das formas alienadas de trabalho humano e de relações sociais de produção impostas pelo modo de produção capitalista. A escola, por si só, não possibilitará tal feito. Mas, sem ela e a efetivação de sua função mediadora na prática social mais ampla tornar-se-á evidente as limitações da atuação dos indivíduos na medida em que os mesmos tenderão a estar alijados do desenvolvimento de suas máximas capacidades humanas.

Desta feita, a pedagogia histórico-crítica tem procurado respaldar o trabalho educativo escolar para que o mesmo mobilize os saberes populares e determinadas atividades da esfera da vida cotidiana para o universo das formas culturais mais elaboradas da ciência, da arte, da filosofia e da política, desejando que "[...] o aluno possa se relacionar conscientemente com esse cotidiano, mediado pela apropriação dos conhecimentos científicos, artísticos, ético-filosóficos e políticos" (DUARTE, 2007, p. 58).

Portanto, estamos defendemos a pedagogia histórico-crítica enquanto teoria pedagógica balizadora do trabalho educativo do MST - e demais movimentos de luta social - por ser ela a teoria da prática educativa a qual vem desenvolvendo a tese de que o processo educativo escolar é um processo criador de carecimentos superiores, voltado para a formação humana dos indivíduos não fundamentada na satisfação das necessidades já dadas pela vida cotidiana dos alunos, mas sim, aquele que produz nos educandos necessidades de nível superior, aquelas que não surgem espontaneamente, mas sim, pelo contato com conteúdos socialmente produzidos e integrantes da esfera da vida nãocotidiana (DUARTE, 2007).

Cabe-nos, neste momento, colocar em discussão, a partir de algumas incursões no campo empírico, a validade da tese da defesa da mediação da escola e do trabalho escolar na apropriação do conhecimento. Para tal, iremos investigar os fundamentos da cultura corporal no Programa de Ensino do componente curricular Educação Física do CEEP Milton Santos, bem como, na transcrição de entrevistas estruturadas realizadas com a professora de Educação Física do CEEP Milton Santos, uma escola pública localizada no interior de um assentamento do MST.

\section{DIALOGANDO COM OS DADOS DA REALIDADE}

Essa pesquisa foi realizada no Centro Estadual de Educação Profissional do Campo Milton Santos (CEEPMS) localizado no Assentamento Terra Vista, situado no município de Arataca, no estado da Bahia. A escola está articulada à DIREC 6, foi fundada em 2009, 
mas só em 2011 se tornou Centro de Educação Profissionalizante, quando foram implementados cinco cursos técnicos. São eles: Agroecologia, Meio Ambiente, Agroindústria, Zootecnia e Informática. Além disso, a escola também disponibiliza o curso de Agroextrativismo, o qual ocorre do $6^{\circ}$ ao $9^{\circ}$ ano do Ensino Fundamental, portanto, não se caracteriza como curso profissionalizante.

Para analisar a organização do trabalho pedagógico no componente curricular Educação Física na escola do assentamento, é necessário identificar inicialmente o entendimento de Educação Física de maneira geral e de que forma a disciplina Educação Física se relaciona com a educação e com a cultura. Outro aspecto a ser identificado para uma análise se refere à teoria pedagógica a qual pauta o trabalho escolar desse componente curricular. E por fim, em que medida a Educação Física se articular aos princípios do Movimento rumo a uma formação para a luta pela emancipação humana.

No entendimento da professora entrevistada a Educação Física está constantemente ligada à educação e a cultura não havendo distinção entre elas. Essa afirmativa pode ser evidenciada em sua fala quando ela diz:

Acredito que a Educação Física está constantemente ligada a educação e a cultura, pois as mesmas não andam distintas. Desde o início da história nas antigas civilizações uma faz parte do processo contínuo de formação e contribuição do homem. Quando se estuda a história de um povo vários elementos são colocados em pauta: localização, linguagem, danças, comidas típicas, os costumes de uma forma geral. E tudo isso perpassa pelo processo de formação humana (Participante 1).

Quanto à forma de organização do trabalho pedagógico da disciplina Educação Física do CEEPMS, é possível evidenciar que alguns conteúdos são afins para todos os cursos como, por exemplo, o esporte. Mas existe também a presença de conteúdos que se referem ao curso específico.

Alguns conteúdos são afins para todos os cursos como, por exemplo, o
esporte. Mas existe também a presença de conteúdos que se referem ao
curso específico. No curso de Informática, são trabalhados os conteúdos
"tecnologia seus aspectos e reflexos na sociedade" e "a tecnologia e o
isolamento social"; no curso de Meio Ambiente, "a relação entre a
Educação Física e o meio ambiente", "caminhada orientada" e "saúde e
qualidade de vida". No curso de Agroecologia "alimentação saudável x
alimentos orgânicos e inorgânicos"e "caminhada orientada"; e por fim,
no curso de Zootecnia "alimentação saudável x manipulação e
manipulação correta de animais (Participante 1).

Entendemos ser necessário ter clareza do objeto de estudo da Educação Física para não descaracterizar tal disciplina curricular e para poder legitimar a sua importância no processo de formação humana. Sabe-se que a Educação Física é uma disciplina que trata, pedagogicamente, na escola, do conhecimento de uma área denominada de cultura corporal.

Na sistematização dos conteúdos dessa disciplina escolar, a organização curricular deve contemplar em seu planejamento pedagógico as mais diversas manifestações da cultura corporal, como o jogo, a dança, o esporte, as lutas e a ginástica. E esses conteúdos devem contribuir para elevar o padrão cultural dos educandos, na medida em que é função desta disciplina curricular transmitir o conhecimento historicamente construído e 
socialmente acumulado acerca deste conjunto de manifestações da corporalidade dos homens (TAFFAREL; ESCOBAR, 2008).

Entretanto, constata-se que o ensino da disciplina escolar Educação Física no Assentamento Terra Vista se dá por meio de projetos de intervenção com os alunos do CEEPMS de diversos cursos. Esses projetos são desenvolvidos para atender a demanda da própria sala de aula, cidades circunvizinhas e da outra escola do assentamento que oferta o ensino fundamental, a Escola Florestan Fernandes. A entrevistada afirma que há um envolvimento mesmo que tímido por parte dela e da disciplina Educação Física com o Assentamento:

\begin{abstract}
Procuro fazer projetos de intervenção com alunos de diversos cursos para aplicar no Florestan nas cidades circunvizinhas e na própria sala de aula com os seguintes temas: Alimentação saudável, reciclagem, artesanato e produtos extrativista e etc. (Participante 1).
\end{abstract}

Reconhecemos a tentativa de se adequar à realidade concreta dos alunos do assentamento, de vincular os conteúdos trabalhados em sala de aula com a vida dos assentados e com as questões do MST, além da busca de se estabelecer uma relação mais próxima com cursos profissionalizantes do CEEPMS e dar sentido ao trabalho pedagógico escolar. Não obstante, pode-se constatar certo esvaziamento no que se refere aos conteúdos e a própria especificidade do objeto de estudo da Educação Física.

Esse esvaziamento dos conteúdos da cultura corporal no planejamento pedagógico da entrevistada reflete também na maneira pela qual esses conhecimentos desenvolvidos nas aulas de Educação Física na escola passam a fazer parte da vida dos assentados nos momentos de tempo livre e lazer. O que queremos dizer é que o trabalho educativo escolar acaba por não cumprir sua função de mediação na prática social global (SAVIANI, 2008).

Em pesquisa realizada por Lavoura (2013) neste mesmo assentamento, evidenciouse que, com relação ao desenvolvimento dos conteúdos da cultura corporal no âmbito do tempo livre e de lazer dos assentados, de maneira geral, não havia uma política de organização para se fazer acontecer a apropriação de seus mais distintos e diversos conteúdos de maneira crítica e criativa. O que se constatou foi que as práticas da cultura corporal acabavam por reproduzir os moldes de organização e valorização de objetivos e conteúdos de vivências e experimentações de maneira indistinta à perspectiva hegemônica posta pela sociabilidade no modo de produção capitalista.

Para o autor, tal política cultural não pode prescindir da escola. Ao contrário, exige sua participação e, mais do que isto, exige que a mesma cumpra sua função social de socialização do saber sistematizado. Conforme Saviani (2008) é necessário que a educação escolar identifique os elementos culturais essenciais os quais necessitam ser assimilados pelos alunos, sobretudo tendo-se em vista as exigências da prática social e a constituição das relações sociais nesta sociedade de classes. Neste sentido:

[...] trata-se de distinguir entre o essencial e o acidental, o principal e o secundário, o fundamental e o acessório. Aqui me parece de grande importância, em pedagogia, a noção de "clássico". O clássico não se confunde com o tradicional e também não se opõe, necessariamente, ao moderno e muito menos ao atual. Clássico é aquilo que se firmou como fundamental, como essencial. Pode, pois, constituir-se num critério útil para a seleção dos conteúdos do trabalho pedagógico (p. 14). 
E tomando-se a escola como uma mediadora da prática social global, visto que a mesma carrega determinações - notadamente quanto à questão do conhecimento e do saber sistematizado - para a prática social dos indivíduos, ela deve estar incluída - e com lugar de destaque - na política cultural mais ampla do MST.

Outro ponto investigado se refere à contribuição dos conhecimentos da cultura corporal para o projeto de formação humana na luta pela emancipação dos homens. Foi perguntando na entrevista de que forma os conteúdos da cultura corporal trabalhados na disciplina Educação Física podem contribuir para o projeto de Emancipação Humana do MST, questão esta que a entrevistada apresentou muitas dificuldades em responder, afirmando ainda não conhecer a produção teórica do MST sobre educação e cultura bem como a política cultural e educacional do MST.

Para a concretização do objetivo de formação dos indivíduos nas suas máximas possibilidades de desenvolvimento e humanização, ainda que nas complexas relações sociais alienantes e alienadas desta sociedade capitalista, é fundamental educar e formar os educadores do próprio $\mathrm{MST}^{5}$. Para superar algumas contradições internas na prática pedagógica dos assentamentos é condição indispensável formar estes educadores, sobretudo para a superação do praticismo e do imediatismo das ações pedagógicas na educação escolar. É necessário o aprofundamento teórico (numa dada teoria do conhecimento e teoria pedagógica), formação política e de consciência de classe voltada aos professores do MST.

Notadamente, essa necessidade teórica não diz respeito a qualquer teoria, visto que há de ser uma teoria a qual dê conta de explicar a realidade a partir das contradições do capitalismo, permitindo apreender as relações sociais realmente existentes e os complexos sociais fundamentais articulados ao processo de produção da existência humana. Ademais, esse aporte teórico deve possibilitar desmitificar as relações concretas presentes no processo de elaboração do conhecimento teórico em sua relação com a produção da existência (a prática social) fundada no trabalho humano.

A teoria pedagógica, pela sua vez, é uma teoria interpretativa e de intervenção da prática pedagógica da escola. É um corpo de categorias que investiga as regularidades subjacentes ao processo de trabalho pedagógico e que medeia as relações entre a teoria educacional e as metodologias específicas, como a Educação Física, destinadas ao ensino dos conteúdos escolares. As categorias que configuram a teoria pedagógica são conceitos explicativos que emergem da própria prática pedagógica e que revelam sua verdadeira natureza e finalidade (BAHIA, 2012, p.49).

De acordo com os Referencias Curriculares do Estado da Bahia para a Educação Física:

Uma teoria pedagógica avançada reconhece a Cultura Corporal como objeto de estudo da disciplina Educação Física, sem perder de vista os objetivos relacionados com a formação corporal, física, dos estudantes, mas situando-os no âmbito da vida real de uma sociedade de classes. Entende-se por avançada uma teoria que defenda a historicidade da cultura e a necessidade da sua preservação através da participação coletiva na sua produção e evolução, no marco de um projeto histórico anticapitalista no qual "cultura" recupere o seu significado real de "resultado da vida e da atividade do homem em busca da sua 
superação". Uma teoria que reconheça a participação da classe trabalhadora na produção da cultura de modo que se preserve a memória nacional e se tenha como perspectiva o desenvolvimento omnilateral. Só assim a Educação Física estará cumprindo sua responsabilidade social e justificando sua razão de ser e de estar na escola (BAHIA, 2012 p.49).

Com efeito, a entrevistada não deixa evidente em seu planejamento qual teoria pedagógica norteia o seu trabalho. Mas é possível identificar pelos seus relatos que a sua prática pedagógica sofre resquícios da pedagogia dos projetos, uma pedagogia embrionária do construtivismo e integrante do quadro das pedagogias do "aprender a aprender". Segundo consta na entrevista:

Procuro fazer projetos de intervenção com os alunos de diversos cursos para aplicar no Florestan, nas cidades circunvizinhas e na própria sala de aula com os seguintes temas: alimentação saudável, reciclagem, artesanato e produtos extrativistas e etc. (Participante 1).

Detectar esse tipo de pedagogia dentro de uma escola - ainda que vinculada à burocracia estatal - de um assentamento do MST traz inúmeras fragilidades para os processos de formação e emancipação humana pretendidos pelo Movimento.

Um primeiro aspecto comum a essas pedagogias do "aprender a aprender" apontado por Duarte (2010) é a ausência da perspectiva de superação da sociedade capitalista. Mesmo que algumas dessas pedagogias em determinados momentos lancem críticas a certos aspectos da sociedade capitalista, tais críticas acabam sendo nulas porque essas teorias acreditam na possibilidade de resolução dos problemas sociais sem a superação radical da lógica de reprodução do capital.

Outra fragilidade que a pedagogia dos projetos traz para a educação é apontada por Duarte (2010) e pode ser detectada na organização curricular do CEEPMS. Trata-se de outra ideia muito difundida por estas pedagogias contemporâneas, a de que o cotidiano do aluno deve ser a referência central para as atividades escolares. Nesse entendimento o conhecimento só tem valor quando pode ser empregado para a resolução de problemas da prática cotidiana. Uma das consequências mais perversas dessa limitação da validade do conhecimento à sua utilidade na prática cotidiana é a reprodução das desigualdades sociais por meio da naturalização de tais desigualdades.

Duarte (2000) afirma que essas pedagogias do "aprender a aprender" possuem certos princípios valorativos comuns, quais sejam: que a aprendizagem tem mais valor quando desencadeada espontaneamente; que o processo de aquisição do conhecimento tem mais valor que seu produto; que o conteúdo escolar pode ser qualquer um, pois não há um conhecimento mais valorizado do que outro (e ainda, tal conteúdo deve estar de acordo com os interesses espontâneos dos alunos) e; que a escola serve para produzir a adaptação dos indivíduos. Assim, o lema "aprender a aprender" desvaloriza o papel da escola como instituição que sistematiza o saber para que outros indivíduos possam se apropriar dele.

Em contraposição a estas teorias pedagógicas, a pedagogia histórico-critica tem buscado nestes últimos 30 anos de existência valorizar a educação escolar e o ato de ensinar, afirmando a necessidade de se garantir os conteúdos os quais permitam aos alunos compreender e participar da sociedade de forma crítica, superando a visão de senso comum, incorporando a experiência inicial do educando ao universo cultural acumulado historicamente pela humanidade (MARSIGLIA, 2011). 
Ao estabelecer a importância da educação escolar e a defesa da transmissão do conhecimento nas suas formas mais desenvolvidas, a pedagogia histórico-crítica está se fundamentando nos pressupostos da psicologia histórico-cultural (cuja principal referência é a obra de Vigotski e sua escola, compondo nomes como os de Leontiev, Galperin, Elkonin e Davidov), afirmando que a educação escolar modifica radicalmente o desenvolvimento e a estrutura das funções psíquicas superiores, reconstituindo suas propriedades e possibilitando-lhes o mais amplo alcance. Nessa direção, o ensino escolar alia-se às condições objetivas de desenvolvimento dessas funções.

De acordo com Facci e Tuleski (2006) o processo de humanização ocorre quando o homem desenvolve essas funções que o diferencia dos animais, partindo do entendimento de que a apropriação da cultura provoca a superação das limitações postas pelo desenvolvimento biológico.

Dessa forma, é necessário oportunizar ao indivíduo, desde os primeiros anos de vida, a apropriação do conhecimento acerca do mundo que o rodeia, organizando sua percepção sobre ele e dirigindo sua atenção, tendo em vista a análise, a discriminação, a síntese, enfim, ativando formas de pensamento nas quais a atenção corrobora para a identificação do essencial, do fundamental, para além do mais atrativo e aparente (MARTINS, 2012).

Nesse sentido, uma das funções da escola na sociedade contemporânea diz respeito à possibilidade de apropriação do pensamento teórico ou conceitual. O pensamento conceitual é o mais importante meio de garantir tal ampliação, ou seja, a apropriação dos conceitos científicos pelo aluno, na escola, é considerada um fator primordial para o seu desenvolvimento (FACCI; TULESKI, 2006).

Se é fato que a educação escolar promove desenvolvimento, também é fato que o desenvolvimento não resulta de qualquer modelo de educação escolar. Portanto, uma educação escolar que vise à formação de indivíduos plenamente desenvolvidos carece primar pelo desenvolvimento do pensamento complexo, superior, na ausência do qual resulta comprometido o ato volitivo e, igualmente, o autocontrole da conduta (MARTINS, 2012).

Diante de tais constatações, reafirmamos a necessidade de que o conhecimento incluindo-se a cultura corporal - seja tratado na educação escolar do MST - e da classe trabalhadora em geral - estando pautado em pressupostos teórico-metodológicos os quais expressem "[...] um conjunto de elementos que, articulados, ampliam nossas possibilidades de abordar a realidade no sentido de sua compreensão, da produção de conhecimentos, do encaminhamento de ações, enfim, de entender, explicar e agir no enfrentamento dos problemas postos pela existência” (SANTOS JÚNIOR et. al., 2009, p. 38).

De igual maneira, apontamos a necessidade de uma teoria pedagógica a qual tenha inspiração no marxismo e, portanto, seja a expressão de uma concepção pedagógica atrelada à concepção de mundo e de homem própria do materialismo histórico-dialético, reconhecidamente a pedagogia histórico-crítica.

\section{CONSIDERAÇÕES FINAIS}

Estamos defendendo a possibilidade da educação do MST estar pautada na pedagogia histórico-crítica como forma de contribuir para a formação dos indivíduos integrantes do Movimento e para o seu projeto de luta. Para tanto, o trabalho educativo escolar deve priorizar a formação teórica dos estudantes, de forma a elevar o patamar intelectual e desenvolver as funções psicológicas superiores necessárias para se superar o pensamento empírico em direção ao pensamento científico. 
Entendemos que a educação escolar poderá contribuir para a transformação radical da sociedade capitalista por meio de um duplo movimento: empreendendo a crítica à educação nas suas formas burguesas e, ao mesmo tempo, reorganizando o trabalho educativo de modo com que ele cumpra com sua função social, qual seja a de transmissão do conhecimento sistematizado. Esta tarefa pode ser assumida pelo MST.

Conforme afirmou o professor Dermeval Saviani:

[...] os educadores que se colocam no campo do marxismo deverão ter clareza de que, se a burguesia se serve do saber elaborado para reforçar sua dominação, isso se deve ao fato de que ela busca se apropriar com exclusividade dessa forma de saber, excluindo dela os trabalhadores. Segue-se, pois, que o saber elaborado é colocado a serviço da burguesia, o que lhe dá a aparência de que se trata do próprio saber burguês. Na medida, porém, em que, pela análise do desenvolvimento histórico propiciado pela teoria marxista, nos damos conta de que o saber elaborado não é inerentemente burguês, mas é produzido pelo conjunto dos homens ao longo da história, nos defrontamos com a seguinte tarefa: desarticular da ideologia burguesa o saber elaborado e rearticulá-lo em torno dos interesses dos trabalhadores. É esse o trabalho que nos cabe desenvolver como educadores, como o têm evidenciado os principais teóricos do marxismo (SAVIANI, 2009b, p. 114-115) (destaque nosso).

Ainda que a educação escolar não transforme por si mesma a sociedade, ela pode contribuir decisivamente na articulação da luta mais ampla por essa transformação, desde que não esteja alinhada às pedagogias comprometidas com a conservação do capitalismo. A ênfase na transmissão dos conhecimentos clássicos, tal como postulado pela pedagogia histórico-crítica, não perde de vista que a teoria, por si mesma, não transforma a realidade. Mas também não perde de vista que essa transformação exige a formação de indivíduos aptos a fazê-lo.

\section{REFERÊNCIAS}

ARAÚJO, M. N. R. As contradições e as possibilidades de construção de uma educação emancipatória no contexto da luta pela terra. Tese de Doutorado (Doutorado em Educação) - Faculdade de Educação, Universidade Federal da Bahia, Salvador, 2007.

ARROYO, M. G. Pedagogias em movimento: o que temos a aprender dos movimentos sociais? Currículo sem Fronteiras, v. 3, n. 1, p. 28-49, jan./jun 2003.

BAHIA. Secretaria de Educação do Estado da Bahia. Referencial Curricular Básico para a Educação Física na Rede Pública Estadual de Educação da Bahia. Superintendência da Educação Básica, Salvador, 2012 (versão preliminar).

CALDART, R. S. Pedagogia do movimento sem terra. 3. ed. São Paulo: Expressão Popular, 2004.

A escola do campo em movimento. Currículo sem Fronteiras, v. 3, n. 1, p. 6081, Jan/Jun 2003. 
D'AGOSTINI, A. A educação do MST no contexto educacional brasileiro. Tese de Doutorado (Doutorado em Educação) - Faculdade de Educação, Universidade Federal da Bahia, Salvador, 2009.

DALMAGRO, S. L. A escola no contexto das lutas do MST. In: VENDRAMINI, C. R.; MACHADO, I. F. (Orgs.). Escola e movimento social: experiências em curso no campo brasileiro. São Paulo: Expressão Popular, 2011, p. 43-78.

DUARTE, N. O debate contemporâneo das teorias pedagógicas. In: MARTINS, L. M.; DUARTE, N. (Orgs.). Formação de professores: limites contemporâneos e alternativas necessárias. São Paulo: Cultura Acadêmica, 2010, p. 33-50.

Educação Escolar, teoria do cotidiano e a escola de Vigotski. 4. ed. Campinas: Autores Associados, 2007.

Vigotski e o "aprender a aprender": crítica às apropriações neoliberais e pósmodernas da teoria vigotskiana. Campinas: Autores Associados, 2000.

A individualidade para-si. Contribuição a uma teoria histórico-social da formação do indivíduo. Campinas: Autores Associados, 1993.

FACCI, M. G. D.; TULESKI, S. C. Da apropriação da cultura ao processo de humanização: o desenvolvimento das funções psicológicas superiores. Anais do II Encontro Brasileiro de Educação e Marxismo. Curitiba, 2006.

ESCOBAR, M. O.; TAFFAREL, C. N. Z. A cultura corporal. In: HERMIDA, Jorge Fernando (Org.). Educação Física: conhecimento e saber escolar. João Pessoa: EDUFPB, 2009, p. 173-180.

GIL, A. C. Métodos e técnicas de pesquisa social. 5. ed. São Paulo: Atlas, 1999.

LAVOURA, T. N. Cultura corporal e tempo livre em áreas de reforma agrária: notas acerca da educação escolar e da emancipação humana. Tese de Doutorado (Doutorado em Educação) - Faculdade de Educação, Universidade Federal de Minas Gerais, Belo Horizonte, 2013.

MARSIGLIA, A. C. G. A prática pedagógica na perspectiva da pedagogia histórico crítica. In: MARSIGLIA, A. C. G. (Org.). Pedagogia histórico-crítica: 30 anos. Campinas: Autores Associados, 2011, p. 101-120.

MARTINS, L. M. O desenvolvimento do psiquismo e a educação escolar: contribuições à luz da psicologia histórico-cultural e da pedagogia histórico-crítica. Tese (Livre Docência) - Departamento de Psicologia, Universidade Estadual Paulista, Bauru, 2012.

MARX, K.; ENGELS, F. A ideologia alemã. São Paulo: Boitempo, 2007. 
MST. 26 anos do Movimento Sem Terra, 2009. Disponível em: <http://www.mst.org.br/node/7702 > Acesso em: 22/08/2012.

2005.

Dossiê MST Escola - Documentos e estudos 1990 - 2001. São Paulo: Iterra,

OLIVEIRA, B. A.; DUARTE, N. A socialização do saber escolar. São Paulo: Cortez, Autores Associados, 1990.

RICHARDSON, R. J. Pesquisa social: métodos e técnicas. São Paulo: Atlas, 1999.

SANTOS, C. F. Pedagogia histórico-crítica e movimentos sociais populares: para além das dicotomias entre práticas educativas escolares e não escolares. In: MARSIGLIA, A. C. G.; BATISTA, E. L. (Orgs.). Pedagogia histórico-crítica: desafios e perspectivas para uma educação transformadora. Campinas: Autores Associados, 2012, p. 181-206.

SANTOS JÚNIOR, C. L. et. al. A base conceitual sobre formação de professores e militantes culturais. In: COLAVOLPE, C. R.; TAFFAREL, C. N. Z.; SANTOS JÚNIOR, C. L. Trabalho pedagógico e formação de professores / militantes culturais: construindo políticas públicas para a Educação Física, esporte e lazer. Salvador: EDUFBA, 2009, p. 33-46.

SAVIANI, D. História das ideias pedagógicas no Brasil. 3. ed. Campinas: Autores Associados, 2011.

Escola e democracia. 41. ed. Campinas: Autores Associados, 2009a.

Modo de produção e pedagogia histórico-crítica. Germinal: Marxismo e Educação em Debate, Londrina, v. 1, n. 1, p. 110-116, jun. 2009 b.

Pedagogia histórico-crítica: primeiras aproximações. 10. ed. São Paulo: Autores Associados, 2008.

Educação: do senso comum à consciência filosófica. 10. ed. São Paulo: Cortez/Autores Associados, 1991.

TAFFAREL, C. N. Z.; ESCOBAR, M. O. Educação Física e movimentos de luta sociais. Faculdade de Educação. Universidade Federal da Bahia, 2008. Disponível em http://www.rascunhodigital.faced.ufba.br. Acesso em 18/07/2010.

TEIXEIRA, D. R. A necessidade histórica da cultura corporal: possibilidades emancipatórias em áreas de reforma agrária - MST/BA. Dissertação (Mestrado em Educação) - Faculdade de Educação, Universidade Federal de Santa Catarina, Florianópolis, 2009.

VENDRAMINI, C. R. Educação e trabalho: reflexões em torno dos movimentos sociais do campo. Cad. Cedes, Campinas, vol. 27, n. 72, p. 121-135, maio/ago. 2007. 


\section{Notas}

${ }^{1}$ Professora especialista da rede estadual de educação básica da Bahia. Integrante do Grupo de Estudos Marxistas em Educação - UESC.

${ }^{2}$ Professora especialista da rede estadual de educação básica da Bahia. Integrante do Grupo de Estudos Marxistas em Educação - UESC.

${ }^{3}$ Professor da Universidade Estadual de Santa Cruz - UESC. Líder do Grupo de Estudos Marxistas em Educação - UESC. Doutor em Educação pela UFMG. E-mail: nicolalavoura@ uol.com.br

${ }^{4}$ Por cultura corporal compreende-se parte da cultura geral a qual é produzida socialmente ao longo da história da humanidade e, se materializa - ganha forma - por meio das brincadeiras, dos jogos, do esporte, da dança, das lutas, da capoeira e da ginástica, dentre outros. Tal cultura corporal, "[...] cuja conexão geral ou primigênia - essência do objeto e o nexo interno das suas propriedades -, determinante do seu conteúdo e estrutura de totalidade, é dada pela materialização em forma de atividades, sejam criativas ou imitativas, das relações múltiplas de experiências ideológicas, políticas, filosóficas e outras, subordinadas a leis históricosociais. O geral dessas atividades é que são valorizadas em si mesmas; seu produto não material é inseparável do ato de sua produção e recebe do homem um valor de uso particular por atender aos seus sentidos lúdicos, estéticos, artísticos, agonísticos, competitivos e outros relacionados à sua realidade e às suas motivações. Elas se realizam com modelos socialmente elaborados que são portadores de significados ideais do mundo objetal, das suas propriedades, relações e nexos descobertos pela prática social conjunta" (ESCOBAR; TAFFAREL, 2009, p. 173-174).

${ }^{5}$ Importante destacar a terceira tese de Marx em suas Teses sobre Feuerbach, ao afirmar que "[...] A doutrina materialista da transformação das circunstâncias e da educação esquece que as circunstâncias são transformadas pelos homens e que o próprio educador tem que ser educado [...]". (MARX; ENGELS, 2007, p. 537) (destaque nosso).

Recebido: outubro/13 $\quad$ Aprovado: julho/14 